\title{
Loneliness and Depression in College Students During the COVID-19 Pandemic: The Role of Boredom and Repetitive Negative Thinking
}

Nathan M. Hager ( $\nabla$ nhage005@odu.edu )

Old Dominion University

Matt R. Judah

University of Arkansas

Alicia L. Milam

Old Dominion University

\section{Research Article}

Keywords: COVID-19, Depression, Loneliness, Boredom, Repetitive Negative Thinking, College Students

Posted Date: June 15th, 2021

DOI: https://doi.org/10.21203/rs.3.rs-101533/v2

License: (c) (1) This work is licensed under a Creative Commons Attribution 4.0 International License.

Read Full License

Version of Record: A version of this preprint was published at International Journal of Cognitive Therapy on April 8th, 2022. See the published version at https://doi.org/10.1007/s41811-022-00135-z. 
Loneliness and Depression in College Students During the COVID-19 Pandemic: The Role of Boredom and Repetitive Negative Thinking

Nathan M. Hager, M.S. ${ }^{1,2}$; Matt R. Judah, Ph.D. ${ }^{3}$; Alicia L. Milam, B.A., B.S. ${ }^{1,2}$

${ }^{1}$ Old Dominion University, Norfolk, VA

${ }^{2}$ Virginia Consortium Program in Clinical Psychology, Norfolk, VA

${ }^{3}$ University of Arkansas, Fayetteville, AR

*Corresponding author:

Nathan M. Hager, MS

Department of Psychology

Old Dominion University

Norfolk, VA 23529

Telephone: (757) 683-4439

Fax: (757) 683-5087

nhage005@odu.edu 


\begin{abstract}
The COVID-19 pandemic triggered increased rates of depression, especially among college students. Due to social distancing guidelines, loneliness has been suspected as a prominent factor in depression during the pandemic. Research is needed to identify possible mechanisms through which loneliness conveys risk for pandemic-era depression. Two potential mechanisms are boredom and repetitive negative thinking (RNT). This study examined cross-sectional associations between depression, loneliness, boredom, and RNT in a sample of college students $(N=199)$ in April 2020 immediately following campus closure. Results showed a serial indirect effect of loneliness on depression through boredom then RNT. Moreover, specific indirect effects of loneliness on depression were found through boredom and RNT, individually. Though limited by the cross-sectional design, these data align with cognitive-behavioral theory and identify boredom and RNT as possible mechanisms of the association between loneliness and depression in college students during the COVID-19 pandemic.
\end{abstract}

Keywords: COVID-19, Depression, Loneliness, Boredom, Repetitive Negative Thinking, College Students 
Loneliness and Depression in College Students During the COVID-19 Pandemic: The Impact of Boredom and Repetitive Negative Thinking

Efforts to control the coronavirus disease 2019 (COVID-19) pandemic through social distancing, lockdowns, and quarantines have raised concerns about the potential mental health consequences, especially depression (Holmes et al., 2020; Yao et al., 2020). Such concerns have proven well-founded as studies have uncovered high rates of depression since the onset of the pandemic around the world (Bäuerle et al., 2020; Fullana et al., 2020; Huang \& Zhoa, 2020; Salari et al., 2020) and in the United States (Fitzpatrick et al., 2020). Depression symptoms during the pandemic have increased compared to periods before the pandemic (Chen et al., 2020; McGinty et al., 2020; Wu et al., 2020), including a tripling of the rate of positive depression screens in the United States (Ettman et al., 2020; Twenge \& Joiner, 2020). Such research points toward the COVID-19 pandemic's parallel crisis: elevated depression.

Previous research cautions that pandemic-related mental health effects can endure after a pandemic ends (Brooks et al., 2020; Jeong et al., 2016; Maunder et al., 2006). As the early months of COVID-19-induced lockdowns passed, high levels of depression in the United States remained stable or increased, even as anxiety levels began to decline (Twenge \& Joiner, 2020). The possibility of persistent effects of the pandemic on depression indicates the importance of understanding risk factors of pandemic-related depression so that interventions can be tailored accordingly (Duan \& Zhu, 2020; Galea et al., 2020). To do this, research should focus on identifying potential mechanisms responsible for pandemic-era depression among vulnerable groups (Holmes et al., 2020). 
College students are vulnerable to the mental impact of the COVID-19 pandemic due to a number of challenges including campus-closures; reduced access to mental health services; diminished independence; delayed graduation; and loss of research, job, and internship opportunities (Aucejo et al., 2020; Gruber et al., 2020; Seidel et al., 2020; Zhai \& Du, 2020). These negative impacts heighten college students' vulnerability to mental health problems, such as depression (Douglas et al., 2020). Consistent with increased risk, college students are exhibiting a surge of depression symptoms. Longitudinal studies show that, compared to before the COVID-19 pandemic, college students' depression has been on the rise, even more so than anxiety symptoms (Elmer et al., 2020; Huckins et al., 2020). Students have reported higher rates of depression than other adult demographic groups during the pandemic (Majumdar et al., 2020; Odriozola-González et al., 2020; Wang, Pan, et al., 2020). This may be due to situational risk factors associated with college students' social isolation (e.g., living alone, amount and type of social contact, and reduced emotional support), implicating loneliness as a potential risk factor for depression in college students during the COVID-19 pandemic (Elmer et al., 2020; Zimmerman et al., 2020).

Loneliness - a perceived deficit in social connection and relationships (Zavaleta et al., 2014) - has been on the radar of mental health experts from the early days of the COVID-19 pandemic due to increases in social isolation (Banerjee \& Rai, 2020; Fiorillo \& Gorwood, 2020). COVID-19 research has shown that loneliness is common among socially isolated individuals (Tull et al., 2020) and is especially prevalent in young adults (Groarke et al., 2020; Li \& Wang, 2020). Loneliness during the pandemic may be particularly problematic for college students because they deeply value socially active campus communities (Cheng, 2004), and typically 
spend more time socializing than any other activity (Arum \& Roksa, 2011; Finlay et al., 2012). However, due to campus closures, about $86 \%$ of college students have experienced social isolation during the pandemic (Son et al., 2020; Wang, Hedge et al., 2020). The critical importance of examining loneliness in college students is highlighted by a longitudinal study showing that the pandemic increased students' feelings of loneliness (Elmer et al., 2020). The majority of college students report greater loneliness as a result of the pandemic (Elmer et al., 2020; Gritsenko et al., 2020). This increased loneliness may play a prominent role in the mental health effects of the pandemic on college students as they endure drastic restrictions on their social activities.

More closely examining loneliness during the COVID-19 pandemic may offer insight into college students' depression, which has been linked to social and interpersonal variables (Alsubaie et al., 2019; Lee et al., 2014; Wright et al., 2014). Loneliness has been related to college student's current depression (e.g., Ceyhan \& Ceyhan, 2011; Doğan et al., 2020; Pervin \& Ferdowshi, 2016; Wright et al., 2014) and future depression (Rich \& Scovel, 1987; Richardson et al., 2017; Wei et al., 2005). The association between loneliness and depression among college students has also been observed during the COVID-19 pandemic (Elmer et al., 2020; Misirlis et al., 2020; Son et al., 2020). When evaluating the temporal relation between loneliness and depression, studies across four college student samples showed that loneliness predicted future depression, while the effect of depression on future loneliness was either nonexistent or significantly smaller (Rich \& Scovel, 1987; Richardson et al., 2017; Vanhalst, Luyckx, Teppers et al., 2012). These studies conclude that loneliness' effect on depression is more robust than vice versa, though one study has shown that the effect of loneliness on depression in college 
students weakens over time (Ren et al., 2020). During the early stage of COVID-19 lockdowns, loneliness predicted subsequent depression more strongly than depression predicted loneliness, though the impact of loneliness on depression weakened, but was still significant, a month later (Groarke et al., 2020). Further, pandemic-induced increases in loneliness are associated with a rise in depression among college students (Elmer et al., 2020) and young adults (Lee et al., 2020). Overall, the extant literature highlights that, despite some evidence of a bidirectional relation between loneliness and depression, the effect of loneliness on depression appears stronger, particularly early in the pandemic. Although loneliness has been identified as an important factor in college students' depression during the COVID-19 pandemic, interventions for loneliness (e.g., attending community events, increasing social interaction, social skills training) may be less available or less effective in light of social distancing requirements. As such, other factors that link loneliness and depression may be more effective treatment targets.

One possible explanation for the link between loneliness and depression is boredom. Boredom is characterized by a disinterest in one's current activities and the associated agitation that prompts the desire for more engaging activity (Barbalet, 1999). The core feature of boredom is largely behavioral in that it refers to "the unfulfilled desire to be engaged in satisfying activity," though emotional and cognitive components of boredom also exist (p. 80; Fahlman, 2013). Boredom has been reported as one of the most common concerns of people under lockdown in previous pandemics (Maunder et al., 2003; Reynolds et al., 2008) and the COVID19 pandemic (Academy of Medical Sciences, 2020; Rohail, 2020), especially for young adults (Barari et al., 2020). Loneliness is associated with boredom in college students (Bovornusvakool et al., 2012; Skues et al., 2016; Tam \& Chan et al., 2019) and, in daily life, it co-occurs with 
boredom more than with other emotions (Chin et al., 2017). Research has not examined the temporal connection between loneliness and boredom, but college students qualitatively report loneliness as one of the leading causes of boredom (Harris, 2000), in line with Weiss' (1973) theory on loneliness that predicts that loneliness triggers boredom. Although experts have proposed loneliness and boredom as related effects of the COVID-19 pandemic (Banerjee \& Rai, 2020; Serafini et al., 2020), empirical examination of the link between loneliness and boredom during the pandemic is needed. Furthermore, research suggests that boredom is associated with depressive symptoms cross-sectionally (Lee \& Zelman, 2019; van Hooff \& van Hooft, 2014;

Wiesner et al., 2005) and predicts depression longitudinally (Spaeth et al., 2015). Cross-sectional data support the link between boredom and depression during the COVID-19 pandemic (Chao et al., 2020; Droit-Volet et al., 2020). While boredom has not previously been tested as a mechanism between loneliness and depression, boredom's connection to both constructs and college students' extensive boredom during the COVID-19 pandemic (Aristovnik et al., 2020) support exploring boredom as a relevant intervention target for the progression from loneliness to depression.

In addition to boredom, repetitive negative thinking (RNT) may explain why loneliness is related to depression. RNT refers to thought about negative topics that is both perseverative and difficult to control (Ehring \& Watkins, 2008). RNT combines the constructs of rumination and worry, which have traditionally been examined separately but have been shown to share a single underlying process encompassed by RNT (Harvey et al., 2004; Ehring \& Watkins, 2008). By focusing on the general process of perseverative negative thinking rather than the specific content of the thoughts, RNT cuts across diagnostic categories. RNT is viewed as a reaction to 
negative circumstances in the past, present, or future (Ehring \& Watkins, 2008), such that RNT may increase in response to the loneliness and boredom experienced by college students during the COVID-19 pandemic. Indeed, research suggests that RNT may be a mechanism through which loneliness confers risk for depression. For example, studies have shown that loneliness has an indirect effect on depression through rumination (Vanhalst, Luyckx, Raes et al., 2012; Zawadzki et al., 2013). Though this indirect effect has not been examined in the context of the COVID-19 pandemic, RNT is significantly associated with loneliness (Hoffart et al., 2020) and depression (Ye, Zhou et al., 2020) during the pandemic. Further, RNT predicts depression longitudinally (Raes, 2012; Topper et al., 2014) and has been causally linked to depression among college students through experiments that manipulate RNT (Blagden \& Craske, 1996; McLaughlin et al., 2007). Thus, considering RNT may provide insight into depression developed during the COVID-19 pandemic.

The role of RNT during the COVID-19 pandemic is also highlighted by its potential to serve as a link between boredom and depression. Boredom is associated with worry in college students (Kelly \& Markos, 2001), and boredom and worry often co-occur in everyday life (Chin et al., 2017). In support of boredom influencing future RNT, one study found that workplace boredom predicted rumination one week later (Sousa \& Neves, 2020). Indeed, researchers suggest that boredom precedes RNT when they theorize that bored individuals may use RNT to meet their need for stimulation (Kelly \& Markos, 2001) or may be prone to engage in RNT as they repeatedly ponder a problem while feeling unable to take action (Mugon et al., 2018). As such, boredom may pave the way for increased RNT due to the decreased attention and spontaneous mind-wandering associated with boredom (Carriere et al., 2008; Isacescu et al., 
2017). RNT's connection to boredom, as well as its previously described role in depression, indicates that RNT may be an important cognitive mechanism of depression during the COVID19 pandemic.

Research on how boredom and RNT are related to loneliness and depression fits within behavioral and cognitive theories of depression. Lewinsohn's (1973) behavioral theory of depression posits that reduced access to positively reinforced behaviors is a primary antecedent to depression. Pandemic-related isolation and loneliness reduced college students' access to many positively reinforced behaviors (e.g., social activities). Students who did not find alternative engaging activities (i.e., experienced boredom) likely struggled to compensate for the loss of positively reinforced behaviors, which may have led to increased depression. Further, Beck's (1963) cognitive model of depression describes negative thinking, triggered by stressors, as leading to depression. In the context of the pandemic, stressors (e.g., loneliness) may fuel negative thinking and increase depressive symptoms, even as boredom expands the opportunity for pondering negative thoughts.

The current study examined the possibility that loneliness may increase risk of depression through associations with boredom and RNT. This cross-sectional study focused on college students during the early weeks of campus closure caused by the pandemic. It was hypothesized that loneliness would be significantly associated with depression and that there would be a serial indirect effect of loneliness on depression explained by boredom and RNT. These effects were expected to be above and beyond the effects of generalized anxiety disorder (GAD) symptoms, which were examined due to GAD's high comorbidity with depression (Hasin et al., 2018) and 
association with loneliness and depression during the COVID-19 pandemic (Hoffart et al., 2020; Misirlis et al., 2020; Tso et al, 2020).

\section{Method}

\section{Setting}

On March 11, 2020, the university—located in Virginia, USA —at which data were collected announced a one-week extension of spring break, a transition to online courses after the break, and the temporary closure of on-campus housing (with a waiver for students that did not have other housing options). Gatherings of over 100 people and student activities were cancelled on March 13, and residence hall closures were extended for the remainder of the semester on March 21. The first confirmed COVID-19 case within the university community was reported on March 27, coinciding with a marked increase in local cases. This was closely followed by a statewide stay-at-home order on March 30 in which residents could leave home only for essential activities. All data were collected between April 4 and April 17.

\section{Participants}

The sample consisted of 199 undergraduate college students (mean age $=22.03$ years) recruited through the psychology department research pool at a large southeastern university. The majority of the participants identified as cisgender women (76.4\%) and were not Latinx (88.9\%). The sample was racially diverse with $45.7 \%$ identifying as White, $35.2 \%$ as Black or African American, and $19.1 \%$ as another race or as multiracial. See Table 1 for additional demographic data. Following campus closure, participants reported increased residence with parents or guardians (59.8\% compared to $17.6 \%$ before campus closure) and decreased residence within the campus community (university housing decreased from $39.2 \%$ to $3.0 \%$ and off- 
campus housing decreased from $42.2 \%$ to $33.7 \%$ ). During the previous two weeks, participants interacted socially (e.g., in-person, phone, video) with a median of 10 individuals and left their residence a median of five times total. Further pandemic-impact data are displayed in Table 1. Among all participants, 36\% met the Patient Health Questionnaire-9 (PHQ-9) cutoff for clinical depression $(\geq 10)$ and $27.6 \%$ met the Generalized Anxiety Disorder-7 (GAD-7) cutoff for GAD $(\geq 10)$. The sample described here $(N=199)$ excludes participants who incorrectly responded to at least one of four attention check questions $(n=36)$ or had missing data on all items of at least one of the study measures $(n=4)$.

\section{Procedure}

The study procedures were approved by the university's Institutional Review Board. Participants provided informed consent before beginning the study. They completed measures online and received research credits in exchange for participating.

\section{Measures}

\section{Demographic and Pandemic Questions}

Participants provided demographic information (i.e., age, gender, ethnicity, race) and completed questions related to the impact of the COVID-19 pandemic. Specifically, participants indicated their pre- and post-campus closure residence and responded to questions about social interactions and freedom-of-movement during the previous two weeks. They also provided information on recent illness-related symptoms and COVID-19 test results.

\section{Depression}

Severity of depressive symptoms was evaluated using the PHQ-9 (Spitzer et al., 1999). This 9-item questionnaire asked participants how often they were bothered by symptoms such as 
"Little interest or pleasure in doing things" and "Feeling down, depressed, or hopeless" in the past two weeks. Items were rated on a 4-point Likert scale ranging from 0 (not at all) to 3 (nearly every day) and were summed such that higher scores indicated more depressive symptoms. Internal consistency was good in the current sample $(\alpha=.85)$.

\section{Loneliness}

Loneliness was assessed with the 10-item UCLA Loneliness Scale (version 3-short; ULS10; Russell, 1996). Participants reported how often they felt detached or alone (e.g. "close to people" and "isolated from others") over the past two weeks on a 4-point Likert scale ranging from 1 (never) to 4 (always). A sum total was calculated after reverse scoring five items, with higher scores indicating more loneliness. Internal consistency was good in the present study ( $\alpha=$ $.86)$.

\section{Boredom}

The 10-item Disengagement subscale of the Multidimensional State Boredom Scale (MSBS-D; Fahlman et al., 2013) was used to measure boredom. The Disengagement subscale was selected because theory and data identify it as the "core component of boredom" (p. 82; Fahlman et al., 2013). This subscale represents the unique features of boredom, while the other subscales measure emotional and cognitive aspects of boredom, which overlap in content with depressive and anxiety symptoms. Further, compared to the other subscales, the Disengagement subscale has the highest factor loading on the scale's boredom latent variable (factor loading = .95; Fahlman et al., 2013). Participants were asked to indicate how they have felt about themselves and their lives over the past two weeks on items such as "I am stuck in a situation that I feel is irrelevant" and "Everything seems repetitive and routine to me." Items were rated on 
a 7-point Likert scale from 1 (strongly disagree) to 7 (strongly agree), with a higher sum score indicating greater boredom. In the present sample, internal consistency was good $(\alpha=.87)$.

\section{Repetitive Negative Thinking}

The frequency of repetitive negative thinking in the past two weeks was assessed with the 15-item Perseverative Thinking Questionnaire (PTQ; Ehring, et al., 2011). Statements such as "Thoughts intrude into my mind" and "I keep thinking about the same issue all the time" were rated on a 5-point Likert scale from 0 (never) to 4 (almost always). Items were summed, and a higher score indicating more RNT. Internal consistency was excellent in the current study ( $\alpha=$ .97).

\section{Anxiety}

The GAD-7 (Spitzer et al., 2006) was used to assess generalized anxiety symptom severity. This 7-item measure asked participants to rate how often they have experienced symptoms such as "Feeling nervous, anxious, or on edge" and "Worrying too much about different things" over the past two weeks on a scale from 0 (not at all) to 3 (nearly every day). Sum totals were calculated, with higher scores reflecting greater anxiety. Internal consistency was excellent $(\alpha=0.91)$.

\section{Analytic Strategy}

The PROCESS macro (version 3.5; Hayes, 2017) was used to estimate bias-corrected bootstrap confidence intervals (CIs) of the indirect effects using 5,000 bootstrap samples. Effects with 95\% CIs that did not include zero were interpreted as significant. The model tested the serial indirect effect of loneliness on depression through boredom and RNT, in that order. The model also included the specific indirect effects through boredom and RNT independent of one 
another. Tests of indirect effects were repeated with generalized anxiety as a covariate. Due to univariate non-normality of study variables (Shapiro-Wilk $p$ s $<.03$ ), Spearman correlations were calculated. Potential multivariate outliers were detected by Studentized Deleted Residuals (SDR), standardized Difference in Fit (DFFITS), and standardized Difference in Betas (DFBETAS) cutoff values (Cousineau \& Chartier, 2010). The spread of DFFITS and DFBETAS values and inspection of scatter plots suggested that 17 cases may have disproportionately influenced at least one parameter estimate. Conducting analyses including and excluding these cases resulted in only minor differences in parameter estimates that did not affect interpretation, so analyses with all participants were reported. Due to violations of the heteroscedasticity assumption, the HC3 estimator of standard errors was used (Davidson \& MacKinnon, 1993).

\section{Results}

All study variables were positively correlated (see Table 2). The hypothesized serial mediation model was examined. Unstandardized coefficients are reported here, and standardized coefficients are displayed in Figure 1. There was a serial indirect effect of loneliness on depression through boredom then RNT, $B=.10$ [CI: .06, .15]. There were also specific indirect effects of loneliness on depression through boredom, $B=.11$ [CI: .05, .18] and through RNT, $B$ $=.12[\mathrm{CI}: .06, .20]$. Accounting for the indirect effects, there was not a significant direct effect of loneliness on depression, $B=.08$ [CI: $-.02, .19]$. The total effect of loneliness, $B=.42$ [CI: .31 , $.52]$ accounted for $22 \%$ of the variance in depression. Contrasts of the indirect effects did not indicate that one effect was larger than any other. There were no interactions among loneliness, boredom, and/or RNT, all $p s>.20$. To test the robustness of the model, analyses were repeated 
with anxiety as a covariate (see Figure 2), and the confidence intervals of the indirect effects were consistent with the original model.

\section{Discussion}

This study proposed that the indirect effects of boredom, followed by RNT, would partially explain the relation between loneliness and depression. This model was tested in college students during the early stage of the COVID-19 pandemic, soon after campus closure drastically altered students' lives. As hypothesized, loneliness was significantly associated with depression, and this relation was explained by a serial indirect effect through boredom and RNT. Specifically, increased loneliness was related to increased boredom, which was associated with more RNT and, in turn, greater depressive symptoms. Boredom and RNT each also independently accounted for part of the association of loneliness with depression. After accounting for the indirect effects, there was not a significant direct effect of loneliness on depression, though the power to detect a direct effect is smaller than the power to detect an indirect effect (Kenny \& Judd, 2014). The indirect effects remained after controlling for generalized anxiety. While the current cross-sectional data are unable to speak to the causal relations between variables, the results highlight the importance of boredom and RNT as potential mechanisms that explain the association between loneliness and depression during COVID-19 pandemic stay-at-home orders. Recent studies have shown an important connection between college students' loneliness and depression during the COVID-19 pandemic (Elmer et al., 2020; Misirlis et al., 2020; Son et al., 2020). The current study is the first to suggest that boredom and RNT together play a role in this connection and it encourages future investigation of the causal relations using prospective studies. 
The findings are timely and important given increased depression among college students in the wake of the COVID-19 pandemic (Huckins et al., 2020; Zimmerman et al., 2020), when social and activity options are limited. Restricted access to social communities in our college sample was reflected by participants' decreased residence in campus communities as well as their limited freedom of movement and access to social interactions. The indirect effect of loneliness through boredom and RNT is important because it links behavioral and cognitive perspectives on depression risk. Consistent with Beck's (1963) notion that negative automatic thoughts explain how depressive symptoms originate in the context of stressful experiences, RNT explained the association of boredom, and more distally loneliness, with depression. The serial indirect effect through boredom and RNT is in line with the idea that boredom creates the context in which RNT may emerge (Kelly \& Markos, 2001; Mugon et al., 2018). Such a connection agrees with previous findings that boredom can foster introspection and selfreflection (Gana et al., 2000; Vodanovich, 2003), thus increasing the opportunity for RNT. In turn, RNT predicts depressive symptoms, as indicated by prospective studies (Raes, 2012; Topper et al., 2014) and the association found in our cross-sectional data.

In addition to the serial indirect effect through boredom and RNT, specific indirect effects indicated that boredom and RNT each uniquely contributed to the relation between loneliness and depression, even when controlling for anxiety. The indirect effect through boredom supports behavioral theories, which recognize that depression risk increases as social and behavioral reinforcement decline (Lewinsohn, 1974). The effect also adds to a growing body of work showing that loneliness and boredom are depression risk factors during the COVID-19 pandemic (Chao et al., 2020; Droit-Volet et al., 2020; Ellmer et al., 2020; Liu et al., 2020). Prior 
to the pandemic, college students spent more time socializing than doing other activities (Arum \& Roksa, 2011; Finlay et al., 2012). As social activity options are limited by the pandemic, and college students are more sedentary than before the pandemic (Huckins et al., 2020), loneliness and boredom both may be consequences. Just as the indirect effect through boredom supports behavioral theories, the indirect effect through RNT supports cognitive theories. Negative cognition explained part of the association of loneliness with depression after accounting for boredom. Overall, these findings uncover potential behavioral and cognitive mechanisms that, together and independently, may explain why loneliness increases risk for depression.

This study raises important implications for clinical practice. In agreement with the broader literature (Kanter et al., 2010; Kircanski et al., 2012), our findings indicate behavioral and cognitive intervention targets. In the context of a pandemic that presents unique psychological challenges for college students, our data can guide therapists who use interventions that focus on increasing social, pleasant, and valued activity (e.g., behavioral activation) as well as those that focus on cognitive mechanisms of depression (e.g., cognitive therapy). When loneliness is found to be a challenging depression treatment target, reducing boredom and RNT may be relevant alternative treatment goals. Given the pandemic-induced barrier of social distancing, boredom and RNT interventions — which do not rely on social engagement-may be more feasible than interventions focused on loneliness and social activity. Addressing boredom may include behavioral activation to increase valued and pleasant activities (Magidson et al., 2020), engagement in challenging activities (Harju et al., 2016), and cognitive reappraisal (Nett et al., 2010). Our findings further indicate that depression during the pandemic 
may be addressed through interventions that reduce RNT, such as rumination-focused cognitivebehavioral therapy and mindfulness-based cognitive therapy (Spinhoven et al., 2018).

This study is not without limitations that constrain its interpretation. The study was crosssectional and is unable to assess causal links between the variables. Although the model was based on prevailing theory and data concerning temporal relations among variables (e.g., that loneliness predicts depression and not vice versa; Rich \& Scovel, 1987; Richardson et al., 2017; Vanhalst, Luyckx, Teppers et al., 2012), other directions of causal relations are plausible (e.g., a bidirectional relation between loneliness and depression; Ren et al., 2020). The findings identify potential mechanisms worthy of follow-up in a longitudinal study, but temporal mediation cannot be assumed from the current study. As such, we apply the term "mediation" only to describe the analyses in familiar language and avoid using "mediation" and other causal terms when interpreting the results. Although the sample is useful for understanding depression in college students who have undergone campus closure during the COVID-19 pandemic, the generalizability to other populations is limited. Generalizability is further limited by the sample consisting predominately of cisgender women, although women in college have been at higher risk for depression, loneliness, and psychological distress during this pandemic (Chang et al., 2020; Elmer et al., 2020; Wang, Hedge, et al., 2020).

In summary, the present study clarifies the association between loneliness and depression in college students during the COVID-19 pandemic. The findings align with theory, previous findings, and the growing recognition that mental health treatment should adapt to specific symptoms that are highlighted by the current pandemic (Bareket-Bojmel et al., 2020). The data extend our understanding by identifying the indirect impact of loneliness on depression through 
boredom and RNT. This study further demonstrates the independent roles of boredom and RNT in understanding the association of loneliness with depression. Clinically, the findings support boredom and RNT as important depression treatment targets during a pandemic that has limited students' options to engage in social activities. 


\section{Conflict of Interest}

The authors have no actual or potential conflicts of interest to report. 


\section{References}

The Academy of Medical Sciences. (2020). Survey results: Understanding people's concerns about the mental health impacts of the COVID-19 pandemic. 2020. http://www.acmedsci.ac.uk/COVIDmentalhealthsurveys

Alsubaie, M. M., Stain, H. J., Webster, L. A., \& Wadman, R. (2019). The role of sources of social support on depression and quality of life for university students. International Journal of Adolescence and Youth, 24(4), 484-496.

https://doi.org/10.1080/02673843.2019.1568887

Aristovnik, A., Keržič, D., Ravšelj, D., Tomaževič, N., \& Umek, L. (2020). Impacts of the COVID-19 pandemic on life of higher education students: A global perspective. Sustainability, 12(20), 1-34. https://doi.org/10.3390/su12208438

Arum, R., \& Roksa, J. (2011). Academically adrift: Limited learning on college campuses. University of Chicago Press.

Aucejo, E. M., French, J. F., Araya, M. P. U., \& Zafar, B. (2020). The impact of COVID-19 on student experiences and expectations: Evidence from a survey (No. w27392). National Bureau of Economic Research. https://doi.org/10.3386/w27392

Banerjee, D., \& Rai, M. (2020). Social isolation in Covid-19: The impact of loneliness. International Journal of Social Psychiatry 66(6), 525-527. https://doi.org/10.1177\%2F0020764020922269

Barari, S., Caria, S., Davola, A., Falco, P., Fetzer, T., Fiorin, S., Hensel, L., Ivchenko, A., Jachimowicz, J., King, G., Kraft-Todd, G., Ledda, A., MacLennan, M., Mutoi, L., Pagani, C., Reutskaja, E., Roth, C., \& Slepoi F. R. (2020, April 5). Evaluating COVID-19 
public health messaging in Italy: Self-reported compliance and growing mental health concerns. medRxiv. https://doi.org/10.1101/2020.03.27.20042820

Bäuerle, A., Teufel, M., Musche, V., Weismüller, B., Kohler, H., Hetkamp, M., Dörrie, N., Schweda, A., \& Skoda, E. M. (2020). Increased generalized anxiety, depression and distress during the COVID-19 pandemic: a cross-sectional study in Germany. Journal of Public Health, 1-7 https://doi.org/10.1093/pubmed/fdaa106

Beck, A. T. (1963). Thinking and depression: I. Idiosyncratic content and cognitive distortions. Archives of General Psychiatry, 9(4), 324-333. https://doi.org/10.1001/archpsyc.1963.01720160014002

Barbalet, J. M. (1999). Boredom and social meaning. The British Journal of Sociology, 50(4), 631-646. https://doi.org/10.1111/j.1468-4446.1999.00631.x

Bareket-Bojmel, L., Shahar, G., \& Margalit, M. (2020). COVID-19-Related Economic Anxiety Is As High as Health Anxiety: Findings from the USA, the UK, and Israel. International Journal of Cognitive Therapy. Advanced online publication, 1-9. https://doi.org/10.1007/s41811-020-00078-3

Blagden, J. C., \& Craske, M. G. (1996). Effects of active and passive rumination and distraction: A pilot replication with anxious mood. Journal of Anxiety Disorders, 10(4), 243-252. https://doi.org/10.1016/0887-6185(96)00009-6

Bovornusvakool, W., Vodanovich, S. J., Ariyabuddhiphongs, K., \& Ngamake, S. T. (2012). Examining the antecedents and consequences of workaholism. The PsychologistManager Journal, 15(1), 56-70. https://doi.org/10.1080/10887156.2012.649994 
Brooks, S. K., Webster, R. K., Smith, L. E., Woodland, L., Wessely, S., Greenberg, N., \& Rubin, G. J. (2020). The psychological impact of quarantine and how to reduce it: rapid review of the evidence. The Lancet, 395(10227), 912-920. https://doi.org/10.1016/S0140$6736(20) 30460-8$

Carriere, J. S., Cheyne, J. A., \& Smilek, D. (2008). Everyday attention lapses and memory failures: The affective consequences of mindlessness. Consciousness and Cognition, 17(3), 835-847. https://doi.org/10.1016/j.concog.2007.04.008

Ceyhan, E., \& Ceyhan, A. A. (2011). Loneliness and depression levels of the students using a university counseling center. Education and Science, 36(160), 81-92.

Chang, J., Yuan, Y., \& Wang, D. (2020). Mental health status and its influencing factors among college students during the epidemic of COVID-19. Journal of Southern Medical University, 40(2), 171-176. https://doi.org/10.12122/j.issn.1673-4254.2020.02.06

Chao, M., Chen, X., Liu, T., Yang, H., \& Hall, B. J. (2020). Psychological distress and state boredom during the COVID-19 outbreak in China: the role of meaning in life and media use. European Journal of Psychotraumatology, 11(1), 1-7. https://doi.org/10.1080/20008198.2020.1769379

Chen, Y., Zhou, H., Zhou, Y., \& Zhou, F. (2020). Prevalence of self-reported depression and anxiety among pediatric medical staff members during the COVID-19 outbreak in Guiyang, China. Psychiatry Research, 288. https://doi.org/10.1016\%2Fj.psychres.2020.113005

Cheng, D. X. (2004). Students' sense of campus community: What it means, and what to do about it. NASPA Journal, 41(2), 216-234. https://doi.org/10.2202/1949-6605.1331 
Chin, A., Markey, A., Bhargava, S., Kassam, K. S., \& Loewenstein, G. (2017). Bored in the USA: Experience sampling and boredom in everyday life. Emotion, 17(2), 359-368. http://doi.org/10.1037/emo0000232

Cousineau, D., \& Chartier, S. (2010). Outliers detection and treatment: a review. International Journal of Psychological Research, 3(1), 58-67. https://doi.org/10.21500/20112084.844

Davidson, R. \& MacKinnon, J. G. (1993). Estimation and Inference in Econometrics. Oxford University Press.

Doğan, T., Çötok, N. A., \& Tekin, E. G. (2011). Reliability and validity of the Turkish Version of the UCLA Loneliness Scale (ULS-8) among university students. Procedia-Social and Behavioral Sciences, 15, 2058-2062. https://doi.org/10.1016/j.sbspro.2011.04.053

Douglas, M., Katikireddi, S. V., Taulbut, M., McKee, M., \& McCartney, G. (2020). Mitigating the wider health effects of covid-19 pandemic response. $B M J, 1-6$. https://doi.org/10.1136/bmj.m1557

Droit-Volet, S., Gil, S., Martinelli, N., Andant, N., Clinchamps, M., Parreira, L., Rouffiac, K., Dambrun, M., Huguet, P., Dubuis, B., Pereira, B., COVISTRESS network, Bouillon, B., \& Dutheil, F. (2020). Time and Covid-19 stress in the lockdown situation: Time free, «Dying» of boredom and sadness. PLoS ONE, 15(8), 1-15. https://doi.org/10.1371/journal.pone.0236465

Duan, L., \& Zhu, G. (2020). Psychological interventions for people affected by the COVID-19 epidemic. The Lancet Psychiatry, 7(4), 300-302. https://doi.org/10.1016/S22150366(20)30073-0 
Ehring, T., \& Watkins, E. R. (2008). Repetitive negative thinking as a transdiagnostic process. International Journal of Cognitive Therapy, 1(3), 192-205. https://doi.org/10.1521/ijct.2008.1.3.192

Ehring, T., Zetsche, U., Weidacker, K., Wahl, K., Schönfeld, S., \& Ehlers, A. (2011). The Perseverative Thinking Questionnaire (PTQ): Validation of a content-independent measure of repetitive negative thinking. Journal of Behavior Therapy and Experimental Psychiatry, 42(2), 225-232. https://doi.org/10.1016/j.jbtep.2010.12.003

Elmer, T., Mepham, K., \& Stadtfeld, C. (2020). Students under lockdown: Comparisons of students' social networks and mental health before and during the COVID-19 crisis in Switzerland. PLoS ONE, 15(7), 1-22. https://doi.org/10.1371/journal.pone.0236337

Ettman, C. K., Abdalla, S. M., Cohen, G. H., Sampson, L., Vivier, P. M., \& Galea, S. (2020). Prevalence of Depression Symptoms in US Adults Before and During the COVID-19 Pandemic. JAMA Network Open, 3(9), 1-12. https://doi.org/10.1001/jamanetworkopen.2020.19686

Fahlman, S. A., Mercer-Lynn, K. B., Flora, D. B., \& Eastwood, J. D. (2013). Development and validation of the multidimensional state boredom scale. Assessment, 20(1), 68-85. https://doi.org/10.1177\%2F1073191111421303

Finlay, A. K., Ram, N., Maggs, J. L., \& Caldwell, L. L. (2012). Leisure activities, the social weekend, and alcohol use: Evidence from a daily study of first-year college students. Journal of Studies on Alcohol and Drugs, 73(2), 250-259. https://doi.org/10.15288/jsad.2012.73.250 
Fitzpatrick, K. M., Harris, C., \& Drawve, G. (2020). Living in the midst of fear: Depressive symptomatology among US adults during the COVID-19 pandemic. Depression and Anxiety. Advanced online publication. https://doi.org/10.1002/da.23080

Folk, D., Okabe-Miyamoto, K., Dunn, E., \& Lyubomirsky, S. (2020). Did social connection decline during the first wave of COVID-19?: The role of extraversion. Collabra: Psychology, 6(1), 1-13. http://doi.org/10.1525/collabra.365

Fiorillo, A., \& Gorwood, P. (2020). The consequences of the COVID-19 pandemic on mental health and implications for clinical practice. European Psychiatry, 63(1). https://doi.org/10.1192/j.eurpsy.2020.35

Fullana, M. A., Hidalgo-Mazzei, D., Vieta, E., \& Radua, J. (2020). Coping behaviors associated with decreased anxiety and depressive symptoms during the COVID-19 pandemic and lockdown. Journal of Affective Disorders, 275. https://doi.org/10.1016/j.jad.2020.06.027

Galea, S., Merchant, R. M., \& Lurie, N. (2020). The mental health consequences of COVID-19 and physical distancing: The need for prevention and early intervention. JAMA Internal Medicine, 180(6), 817-818. https://doi.org/10.1001/jamainternmed.2020.1562

Gana, K., Deletang, B., \& Metais, L. (2000). Is boredom proneness associated with introspectiveness?. Social Behavior \& Personality: An International Journal, 28(5). https://doi.org/10.2224/sbp.2000.28.5.499

Gritsenko, V., Skugarevsky, O., Konstantinov, V., Khamenka, N., Marinova, T., Reznik, A., \& Isralowitz, R. (2020). COVID 19 Fear, Stress, Anxiety, and Substance Use Among Russian and Belarusian University Students. International Journal of Mental Health and Addiction, 1. https://doi.org/10.1007/s11469-020-00330-z 
Groarke, J., Berry, E., Wisener, L. G., McKenna-Plumley, P., McGlinchey, E., \& Armour, C. (2020). Loneliness in the UK during the COVID-19 pandemic: Cross-sectional results from The COVID-19 Psychological Wellbeing Study. PLoS ONE, 15(9), 1-18. https://doi.org/10.1371/journal.pone.0239698

Groarke, J., McGlinchey, E., McKenna-Plumley, P., Berry, E., Wisener, L. G., \& Armour, C. (2020, November 20). Examining temporal interactions between loneliness and depressive symptoms and the mediating role of emotion regulation difficulties among UK residents during the COVID-19 lockdown: Longitudinal results from the COVID-19 Psychological Wellbeing Study. PsyArXiv. https://doi.org/10.31234/osf.io/gzsjh

Gruber, J., Prinstein, M. J., Clark, L. A., Rottenberg, J., Abramowitz, J. S., Albano, A. M., Aldao, A., Borelli, J. L., Chung, T., Davila, J., Forbes, E. E., Gee, D. G., Hall, G. C. N., Hallion, L. S., Hinshaw, S. P., Hofmann, S. G., Hollon, S. D., Joormann, J., Kazdin, A. E., ... Weinstock, L. M. (2020). Mental health and clinical psychological science in the time of COVID-19: Challenges, opportunities, and a call to action. American Psychologist. Advanced online publication. http://doi.org/10.1037/amp0000707

Harju, L. K., Hakanen, J. J., \& Schaufeli, W. B. (2016). Can job crafting reduce job boredom and increase work engagement? A three-year cross-lagged panel study. Journal of Vocational Behavior, 95-96, 11-20. https://doi.org/10.1016/j.jvb.2016.07.001

Harris, M. B. (2000). Correlates and characteristics of boredom proneness and boredom. Journal of Applied Social Psychology, 30(3), 576-598. https://doi.org/10.1111/j.15591816.2000.tb02497.x 
Harvey, A. G., Watkins, E., Mansell, W., \& Shafran, R. (2004). Cognitive behavioural processes across psychological disorders. Oxford University Press.

Hasin, D. S., Sarvet, A. L., Meyers, J. L., Saha, T. D., Ruan, W. J., Stohl, M., \& Grant, B. F. (2018). Epidemiology of adult DSM-5 major depressive disorder and its specifiers in the United States. JAMA Psychiatry, 75(4), 336-346. https://doi.org/10.1001/jamapsychiatry.2017.4602

Hayes, A. F. (2017). Introduction to mediation, moderation, and conditional process analysis: A regression-based approach. Guilford Publications.

Hoffart, A., Johnson, S. U., \& Ebrahimi, O. V. (2020). Loneliness and social distancing during the COVID-19 pandemic: Risk factors and associations with psychopathology. Frontiers in Psychiatry, 11, 1-9. https://doi.org/10.3389/fpsyt.2020.589127

Holmes, E. A., O'Connor, R. C., Perry, V. H., Tracey, I., Wessely, S., Arseneault, L., Ballard, C., Christensen, H., Cohen Silver, C., Everall, I., Ford, T., John, A., Kabir, T., King, K., Madan, I., Michie, S., Przybylski, A. K., Shafran, R., Sweeney, A., . . Bullmore, E. (2020). Multidisciplinary research priorities for the COVID-19 pandemic: a call for action for mental health science. The Lancet Psychiatry, 7(6), 547-560. https://doi.org/10.1016/S2215-0366(20)30168-1

Huang, Y., \& Zhao, N. (2020). Generalized anxiety disorder, depressive symptoms and sleep quality during COVID-19 outbreak in China: a web-based cross-sectional survey. Psychiatry Research, 228. https://doi.org/10.1016/j.psychres.2020.112954

Huckins, J. F., daSilva, A. W., Wang, W., Hedlund, E., Rogers, C., Nepal, S. K., Wu, J., Obuchi, M., Murphy, E. I., Meyer, M. L., Wagner, D., Holtzheimer, P. E., . . \& Campbell, A. T. 
(2020). Mental Health and Behavior of College Students During the Early Phases of the COVID-19 Pandemic: Longitudinal Smartphone and Ecological Momentary Assessment Study. Journal of Medical Internet Research, 22(6). https://doi.org/10.2196/20185

Isacescu, J., Struk, A. A., \& Danckert, J. (2017). Cognitive and affective predictors of boredom proneness. Cognition and Emotion, 31(8), 1741-1748. https://doi.org/10.1080/02699931.2016.1259995

Jeong, H., Yim, H. W., Song, Y. J., Ki, M., Min, J. A., Cho, J., \& Chae, J. H. (2016). Mental health status of people isolated due to Middle East Respiratory Syndrome. Epidemiology and Health, 38, 1-7. https://doi.org/10.4178\%2Fepih.e2016048

Kanter, J. W., Manos, R. C., Bowe, W. M., Baruch, D. E., Busch, A. M., \& Rusch, L. C. (2010). What is behavioral activation?: A review of the empirical literature. Clinical Psychology Review, 30(6), 608-620. https://doi.org/10.1016/j.cpr.2010.04.001

Kelly, W. E., \& Markos, P. A. (2001). The role of boredom in worry: An empirical investigation with implications for counsellors. Guidance and Counselling, 16(3), 81-85.

Kenny, D. A., \& Judd, C. M. (2014). Power anomalies in testing mediation. Psychological Science, 25(2), 334-339. https://doi.org/10.1177\%2F0956797613502676

Kircanski, K., Joormann, J., \& Gotlib, I. H. (2012). Cognitive aspects of depression. Wiley Interdisciplinary Reviews: Cognitive Science, 3(3), 301-313. https://doi.org/10.1002/wcs.1177

Lee, C. M., Cadigan, J. M., \& Rhew, I. C. (2020). Increases in loneliness among young adults during the COVID-19 pandemic and association with increases in mental health 
problems. Journal of Adolescent Health, 67(5), 714-717.

https://doi.org/10.1016/j.jadohealth.2020.08.009

Lee, C., Dickson, D. A., Conley, C. S., \& Holmbeck, G. N. (2014). A closer look at self-esteem, perceived social support, and coping strategy: a prospective study of depressive symptomatology across the transition to college. Journal of Social and Clinical Psychology, 33(6), 560-585. https://doi.org/10.1521/jscp.2014.33.6.560

Lee, F. K., \& Zelman, D. C. (2019). Boredom proneness as a predictor of depression, anxiety and stress: The moderating effects of dispositional mindfulness. Personality and Individual Differences, 146, 68-75. https://doi.org/10.1016/j.paid.2019.04.001

Lewinsohn, P. M. (1974). A behavioral approach to depression. In R. J. Friedman, \& M. M. Katz (Eds.), The psychology of depression: Contemporary theory and research (pp. 157-178). John Wiley \& Sons.

Li, L. Z., \& Wang, S. (2020). Prevalence and predictors of general psychiatric disorders and loneliness during COVID-19 in the United Kingdom. Psychiatry Research, 291, 1-6. https://doi.org/10.1016/j.psychres.2020.113267

Liu, C. H., Zhang, E., Wong, G. T. F., \& Hyun, S. (2020). Factors associated with depression, anxiety, and PTSD symptomatology during the COVID-19 pandemic: Clinical implications for US young adult mental health. Psychiatry Research, 290, 1-7. https://doi.org/10.1016/j.psychres.2020.113172

Magidson, J. F., Andersen, L. S., Satinsky, E. N., Myers, B., Kagee, A., Anvari, M., \& Joska, J. A. (2020). "Too much boredom isn't a good thing”: Adapting behavioral activation for 
substance use in a resource-limited South African HIV care setting. Psychotherapy, 57(1), 107-118. https://doi.org/10.1037/pst0000257

Majumdar, P., Biswas, A., \& Sahu, S. (2020). COVID-19 pandemic and lockdown: cause of sleep disruption, depression, somatic pain, and increased screen exposure of office workers and students of India. Chronobiology International, 1-10. https://doi.org/10.1080/07420528.2020.1786107

Martin, M., Sadlo, G., \& Stew, G. (2006). The phenomenon of boredom. Qualitative Research in Psychology, 3, 193-211. https://doi.org/10.1191/1478088706qrp066oa

Maunder, R. G., Lancee, W. J., Balderson, K. E., Bennett, J. P., Borgundvaag, B., Evans, S., Fernandes, C. M. B., Goldbloom, D. S., Gupta, M., Hunter, J. J., McGillis Hall, L., Nagle, L. M., Pain, C. Peczeniuk, S. S., Raymond, G., Read, N., Rourke, S. B., Steinberg, R. J., Stewart, T. E., . . \& \& Wasylenki, D. A. (2006). Long-term psychological and occupational effects of providing hospital healthcare during SARS outbreak. Emerging Infectious Diseases, 12(12), 1924-1932. https://doi.org/10.3201\%2Feid1212.060584

Maunder, R., Hunter, J., Vincent, L., Bennett, J., Peladeau, N., Leszcz, M., Sadavoy, J., Verhaeghe, L. M., Steinberg, R., . . \& Mazzulli, T. (2003). The immediate psychological and occupational impact of the 2003 SARS outbreak in a teaching hospital. CMAJ, 168(10), 1245-1251. Retrieved from https://www.cmaj.ca/

McGinty, E. E., Presskreischer, R., Han, H., \& Barry, C. L. (2020). Psychological Distress and Loneliness Reported by US Adults in 2018 and April 2020. JAMA, 324(1), 93-94. https://doi.org/10.1001/jama.2020.9740 
McLaughlin, K. A., Borkovec, T. D., \& Sibrava, N. J. (2007). The effects of worry and rumination on affect states and cognitive activity. Behavior Therapy, 38(1), 23-38. https://doi.org/10.1016/j.beth.2006.03.003

Misirlis, N., Zwaan, M. H., \& Weber, D. (2020). International students' loneliness, depression and stress levels in COVID-19 crisis. The role of social media and the host university. Journal of Contemporary Education Theory \& Research, 4(2), 20-25. https//:doi.org/10.5281/zenodo.4256624.

Mugon, J., Struk, A., \& Danckert, J. (2018). A failure to launch: Regulatory modes and boredom proneness. Frontiers in Psychology, 9, 1-7. https://doi.org/10.3389/fpsyg.2018.01126

Nett, U. E., Goetz, T., \& Daniels, L. M. (2010). What to do when feeling bored?: Students' strategies for coping with boredom. Learning and Individual Differences, 20(6), 626-638. https://doi.org/10.1016/j.lindif.2010.09.004

Odriozola-González, P., Planchuelo-Gómez, Á., Irurtia, M. J., \& de Luis-García, R. (2020). Psychological effects of the COVID-19 outbreak and lockdown among students and workers of a Spanish university. Psychiatry Research, 290, 1-8. https://doi.org/10.1016/j.psychres.2020.113108

Pervin, M. M., \& Ferdowshi, N. (2016). Suicidal ideation in relation to depression, loneliness and hopelessness among university students. Dhaka University Journal of Biological Sciences, 25(1), 57-64. https://doi.org/10.3329/dujbs.v25i1.28495

Raes, F. (2012). Repetitive negative thinking predicts depressed mood at 3-year follow-up in students. Journal of Psychopathology and Behavioral Assessment, 34(4), 497-501. https://doi.org/10.1007/s10862-012-9295-4 
Ren, L., Mo, B., Liu, J., \& Li, D. (2020). A cross-lagged regression analysis of loneliness and depression: A two-year trace. European Journal of Developmental Psychology.

Advanced online publication. https://doi.org/10.1080/17405629.2020.1865146

Reynolds, D. L., Garay, J. R., Deamond, S. L., Moran, M. K., Gold, W., \& Styra, R. (2008).

Understanding, compliance and psychological impact of the SARS quarantine experience. Epidemiology \& Infection, 136(7), 997-1007.

https://doi.org/10.1017/S0950268807009156

Rich, A. R., \& Scovel, M. (1987). Causes of depression in college students: A cross-lagged panel correlational analysis. Psychological Reports, 60(1), 27-30. https://doi.org/10.2466\%2Fpr0.1987.60.1.27

Richardson, T., Elliott, P., \& Roberts, R. (2017). Relationship between loneliness and mental health in students. Journal of Public Mental Health, 16(2), 48-54. https://doi.org/10.1108/JPMH-03-2016-0013

Rohail, I. (2020). Impact of Lock down due to COVID-19 Pandemic on General Public in Pakistan. Foundation University Journal of Psychology, 4(2), 5-10. https://doi.org/10.33897/fujp.v4i2.186

Russell, D. W. (1996). UCLA Loneliness Scale (Version 3): Reliability, validity, and factor structure. Journal of Personality Assessment, 66(1), 20-40. https://doi.org/10.1207/s15327752jpa6601_2

Salari, N., Hosseinian-Far, A., Jalali, R., Vaisi-Raygani, A., Rasoulpoor, S., Mohammadi, M., Rasoulpoor, S., \& Khaledi-Paveh, B. (2020). Prevalence of stress, anxiety, depression among the general population during the COVID-19 pandemic: a systematic review and 
meta-analysis. Globalization and Health, 16(1), 1-11. https://doi.org/10.1186/s12992020-00589-w

Seidel, E. J., Mohlman, J., Basch, C. H., Fera, J., Cosgrove, A., \& Ethan, D. (2020). Communicating mental health support to college students during COVID-19: An exploration of website messaging. Journal of Community Health. Advanced online publication. https://doi.org/10.1007/s10900-020-00905-w

Serafini, G., Parmigiani, B., Amerio, A., Aguglia, A., Sher, L., \& Amore, M. (2020). The psychological impact of COVID-19 on the mental health in the general population. QJM: An International Journal of Medicine, 113(8), 531-537. https://doi.org/10.1093/qjmed/hcaa201

Skues, J., Williams, B., Oldmeadow, J., \& Wise, L. (2016). The effects of boredom, loneliness, and distress tolerance on problem internet use among university students. International Journal of Mental Health and Addiction, 14(2), 167-180. https://doi.org/10.1007/s11469015-9568-8

Son, C., Hegde, S., Smith, A., Wang, X., \& Sasangohar, F. (2020). Effects of COVID-19 on college students' mental health in the United States: Interview survey study. Journal of Medical Internet Research, 22(9), 1-14. https://doi.org/10.2196/21279

Sousa, T., \& Neves, P. (2020). Two tales of rumination and burnout: Examining the effects of boredom and overload. Applied Psychology. Advanced online publication. https://doi.org/10.1111/apps.12257

Spaeth, M., Weichold, K., \& Silbereisen, R. K. (2015). The development of leisure boredom in early adolescence: Predictors and longitudinal associations with delinquency and 
depression. Developmental Psychology, 51(10), 1380-1394.

https://doi.org/10.1037/a0039480

Spinhoven, P., Klein, N., Kennis, M., Cramer, A. O., Siegle, G., Cuijpers, P., Ormel, J., Hollon, S. D., \& Bockting, C. L. (2018). The effects of cognitive-behavior therapy for depression on repetitive negative thinking: A meta-analysis. Behaviour Research and Therapy, 106, 71-85. https://doi.org/10.1016/j.brat.2018.04.002

Spitzer, R. L., Kroenke, K., Williams, J. B., \& Löwe, B. (2006). A brief measure for assessing generalized anxiety disorder: The GAD-7. Archives of Internal Medicine, 166(10), 10921097. https://doi.org/10.1001/archinte.166.10.1092

Spitzer, R. L., Kroenke, K., Williams, J. B. W., \& the Patient Health Questionnaire Primary Care Study Group. (1999). Validity and utility of a self-report version of PRIME-MD: The PHQ Primary Care Study. JAMA, 282(18), 1737-1744. https://doi.org/10.1001/jama.282.18.1737

Tam, K. Y., \& Chan, C. S. (2019). The effects of lack of meaning on trait and state loneliness: Correlational and experience-sampling evidence. Personality and Individual Differences, 141, 76-80. https://doi.org/10.1016/j.paid.2018.12.023

Topper, M., Molenaar, D., Emmelkamp, P. M., \& Ehring, T. (2014). Are rumination and worry two sides of the same coin? A structural equation modelling approach. Journal of Experimental Psychopathology, 5(3), 363-381. https://doi.org/10.5127\%2Fjep.038813

Tso, I. F., \& Park, S. (2020). Alarming levels of psychiatric symptoms and the role of loneliness during the COVID-19 epidemic: A case study of Hong Kong. Psychiatry Research. Psychiatry Research. 293, 1-8. https://doi.org/10.1016/j.psychres.2020.113423 
Tull, M. T., Edmonds, K. A., Scamaldo, K., Richmond, J. R., Rose, J. P., \& Gratz, K. L. (2020). Psychological outcomes associated with stay-at-home orders and the perceived impact of COVID-19 on daily life. Psychiatry Research, 289 1-6. https://doi.org/10.1016/j.psychres.2020.113098

Twenge, J. M., \& Joiner, T. E. (2020). US Census Bureau-assessed prevalence of anxiety and depressive symptoms in 2019 and during the 2020 COVID-19 pandemic. Depression and Anxiety. Advanced online publication. https://doi.org/10.1002/da.23077

Vanhalst, J., Luyckx, K., Raes, F., \& Goossens, L. (2012). Loneliness and depressive symptoms: The mediating and moderating role of uncontrollable ruminative thoughts. The Journal of Psychology, 146(1-2), 259-276. https://doi.org/10.1080/00223980.2011.555433

Vanhalst, J., Luyckx, K., Teppers, E., \& Goossens, L. (2012). Disentangling the longitudinal relation between loneliness and depressive symptoms: Prospective effects and the intervening role of coping. Journal of Social and Clinical Psychology, 31(8), 810-834. https://doi.org/10.1521/jscp.2012.31.8.810

van Hooff, M. L., \& van Hooft, E. A. (2014). Boredom at work: Proximal and distal consequences of affective work-related boredom. Journal of Occupational Health Psychology, 19(3), 348-359. http://doi.org/10.1037/a0036821

Van Tilburg, W. A., \& Igou, E. R. (2012). On boredom: Lack of challenge and meaning as distinct boredom experiences. Motivation and Emotion, 36(2), 181-194. https://doi.org/10.1007/s11031-011-9234-9

Vodanovich, S. J. (2003). On the possible benefits of boredom: A neglected area in personality research. Psychology and Education: An Interdisciplinary Journal, 40(3-4), 28-33. 
Wang, X., Hegde, S., Son, C., Keller, B., Smith, A., \& Sasangohar, F. (2020). Investigating mental health of US college students during the COVID-19 pandemic: Cross-sectional survey study. Journal of Medical Internet Research, 22(9), 1-11. http://doi.org/10.2196/22817

Wang, C., Pan, R., Wan, X., Tan, Y., Xu, L., Ho, C. S., \& Ho, R. C. (2020). Immediate psychological responses and associated factors during the initial stage of the 2019 coronavirus disease (COVID-19) epidemic among the general population in China. International Journal of Environmental Research and Public Health, 17(5). https://doi.org/10.3390/ijerph17051729

Wei, M., Russell, D. W., \& Zakalik, R. A. (2005). Adult attachment, social self-efficacy, selfdisclosure, loneliness, and subsequent depression for freshman college students: A longitudinal study. Journal of Counseling Psychology, 52(4), 602-614. https://doi.org/10.1037/0022-0167.52.4.602

Wiesner, M., Windle, M., \& Freeman, A. (2005). Work stress, substance use, and depression among young adult workers: an examination of main and moderator effect model. Journal of Occupational Health Psychology, 10(2), 83.

Wright, K. B., King, S., \& Rosenberg, J. (2014). Functions of social support and self-verification in association with loneliness, depression, and stress. Journal of Health Communication, 19(1), 82-99. https://doi.org/10.1080/10810730.2013.798385

Wu, Y., Zhang, C., Liu, H., Duan, C., Li, C., Fan, J., Li, H., Chen, L., Xu, H., Li, X., Guo, Y., Wang, Y., Li, X., Li, J., Zhang, T., You, Y., Li, H., Yang, S., Tao, X., . . Huang, H. (2020). Perinatal depressive and anxiety symptoms of pregnant women along with 
COVID-19 outbreak in China. American Journal of Obstetrics and Gynecology. https://doi.org/10.1016\%2Fj.ajog.2020.05.009

Yao, H., Chen, J. H., \& Xu, Y. F. (2020). Patients with mental health disorders in the COVID-19 epidemic. The Lancet Psychiatry, 7(4). https://doi.org/10.1016/S2215-0366(20)30090-0

Ye, B., Zhou, X., Im, H., Liu, M., Wang, X. Q., \& Yang, Q. (2020). Epidemic Rumination and Resilience on College Students' Depressive Symptoms During the COVID-19 Pandemic: The Mediating Role of Fatigue. Frontiers in Public Health, 8, 1-10. https://doi.org/10.3389/fpubh.2020.560983

Zavaleta, D., \& Samuel, K., Mills, C. (2014). Social isolation: A conceptual and measurement proposal. Oxford University. https://doi.org/10.35648/20.500.12413/11781/ii029

Zawadzki, M. J., Graham, J. E., \& Gerin, W. (2013). Rumination and anxiety mediate the effect of loneliness on depressed mood and sleep quality in college students. Health Psychology, 32(2), 212-222. https://doi.org/10.1037/a0029007

Zhai, Y., \& Du, X. (2020). Addressing collegiate mental health amid COVID-19 pandemic. Psychiatry Research, 288, 1-2. https://doi.org/10.1016/j.psychres.2020.113003

Zimmermann, M., Bledsoe, C., \& Papa, A. (2020, June 17). The impact of the COVID-19 pandemic on college student mental health: A longitudinal Eeamination of risk and protective factors. PsyArXiv. https://doi.org/10.31234/osf.io/2y7hu 
Table 1.

Sample Characteristics.

\begin{tabular}{|c|c|c|c|}
\hline & $\begin{array}{l}\text { Mean } \\
(\mathrm{SD})\end{array}$ & Median & $\begin{array}{c}\text { Frequency } \\
\text { (Percentage) }\end{array}$ \\
\hline Age $($ range $=18-63$ years $)$ & $22.03(5.27)$ & & \\
\hline \multicolumn{4}{|l|}{ Gender } \\
\hline Cisgender Man & & & $41(20.6 \%)$ \\
\hline Cisgender Woman & & & $152(76.4 \%)$ \\
\hline Transgender Man & & & $1(.5 \%)$ \\
\hline Transgender Woman & & & $0(0 \%)$ \\
\hline No label & & & $1(.5 \%)$ \\
\hline Prefer not to answer & & & $4(2.0 \%)$ \\
\hline \multicolumn{4}{|l|}{ Ethnicity } \\
\hline Latinx & & & $22(11.1 \%)$ \\
\hline Not Latinx & & & $177(88.9 \%)$ \\
\hline \multicolumn{4}{|l|}{ Race } \\
\hline White or Caucasian & & & $91(45.7 \%)$ \\
\hline Black or African American & & & $70(35.2 \%)$ \\
\hline $\begin{array}{l}\text { American Indian, Native American, } \\
\text { or Alaskan Native }\end{array}$ & & & $1(.5 \%)$ \\
\hline Arab, Middle Eastern, or Arab American & & & $1(.5 \%)$ \\
\hline Asian or Asian American & & & $9(4.5 \%)$ \\
\hline Pacific Islander & & & $1(.5 \%)$ \\
\hline Other & & & $5(2.5 \%)$ \\
\hline Multiracial & & & $21(10.6 \%)$ \\
\hline \multicolumn{4}{|l|}{ Housing before campus closure } \\
\hline University housing or residence hall & & & $78(39.2 \%)$ \\
\hline Off campus housing & & & $84(42.2 \%)$ \\
\hline Parent's or guardian's residence & & & $35(17.6 \%)$ \\
\hline Other & & & $2(1.0 \%)$ \\
\hline \multicolumn{4}{|l|}{ Housing after campus closure } \\
\hline University housing or residence hall & & & $6(3.0 \%)$ \\
\hline Off campus housing & & & $67(33.7 \%)$ \\
\hline Parent's or guardian's residence & & & $119(59.8 \%)$ \\
\hline Other & & & $7(3.5 \%)$ \\
\hline \multicolumn{4}{|l|}{ In the past 2 weeks: } \\
\hline \# of times left your residence & & 5 & \\
\hline Average hours away from residence per day & & 2 & \\
\hline \# of people living at your residence & & 3 & \\
\hline $\begin{array}{l}\text { \# of people interacted with socially (all } \\
\text { methods, e.g., phone, video, in-person) }\end{array}$ & & 10 & \\
\hline Places gone when away from residence: & & & \\
\hline
\end{tabular}




\begin{tabular}{lc}
\hline Grocery store & $174(87.4 \%)$ \\
Outside space/destination & $83(41.7 \%)$ \\
Relative or friend's residence & $78(39.2 \%)$ \\
Restaurant - take-out & $75(37.7 \%)$ \\
Restaurant - dine-in & $1(0.5 \%)$ \\
Workplace & $56(28.1 \%)$ \\
Medical facility & $16(8.0 \%)$ \\
Religious gathering & $3(1.5 \%)$ \\
School & $2(1.0 \%)$ \\
Recreation facility/gym & $1(0.5 \%)$ \\
Other & $2(1.0 \%)$ \\
Never left my residence & $6(3.0 \%)$ \\
Any illness-related symptoms & $25(12.6 \%)$ \\
Ever been tested for COVID-19: & \\
Yes (and result = negative) & $4(2.0 \%)$ \\
No & $195(98.0 \%)$ \\
\hline Note. SD $=$ Standard deviation. The median was used instead of the mean for variables with \\
extreme outliers.
\end{tabular}


Table 2.

Spearman correlations, means, and standard deviations of study variables.

\begin{tabular}{lccccc}
\hline \multicolumn{1}{c}{ Variable } & 1 & 2 & 3 & 4 & 5 \\
\hline 1. Loneliness & -- & & & & \\
2. Boredom & $.52 * * *$ & -- & & & \\
3. RNT & $.49 * * *$ & $.55^{* * *}$ & -- & & \\
4. Depression & $.48^{* * *}$ & $.61^{* * *}$ & $.68^{* * *}$ & -- & \\
5. Anxiety & $.44 * * *$ & $.49 * * *$ & $.71 * * *$ & $.75 * * *$ & -- \\
\hline Mean & 20.51 & 45.93 & 26.72 & 8.04 & 6.49 \\
$S D$ & 6.07 & 11.87 & 14.60 & 5.39 & 5.40 \\
\hline
\end{tabular}

Note. $* * * \mathrm{p}<.001$. Loneliness $=$ UCLA Loneliness total score. Boredom = Multi-dimensional Boredom Scale-Disengaged total score. RNT = Perseverative Thinking Questionnaire total score. Depression $=$ Patient Health Questionniare-9 total score. Anxiety = General Anxiety Disorder-7 total score. 


\section{Figure 1.}

Indirect effects of loneliness on depression.

[Figure 1 inserted here]

Note. Coefficients are standardized. $* * * \mathrm{p}<.001$. The direct effect of Loneliness on Depression is displayed in parentheses following the total effect. 


\section{Figure 2.}

Indirect effects of loneliness on depression with anxiety as a covariate.

[Figure 2 inserted here]

Note. Coefficients are standardized. ${ }^{* * *} \mathrm{p}<.001,{ }^{* *} \mathrm{p}<.01,{ }^{*} \mathrm{p}<.05$. The direct effects of

Loneliness and Anxiety on Depression are displayed in parentheses following the total effects 


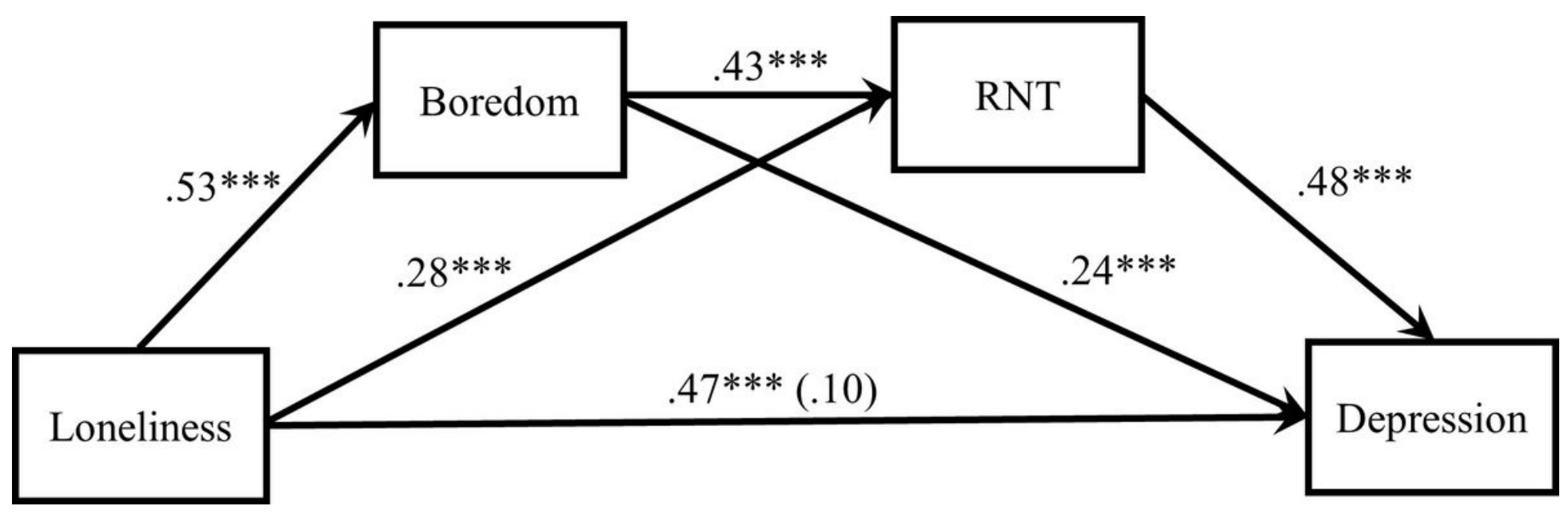

Figure 1

Indirect effects of loneliness on depression. Note. Coefficients are standardized. ${ }^{\star \star *} p<.001$. The direct effect of Loneliness on Depression is displayed in parentheses following the total effect.

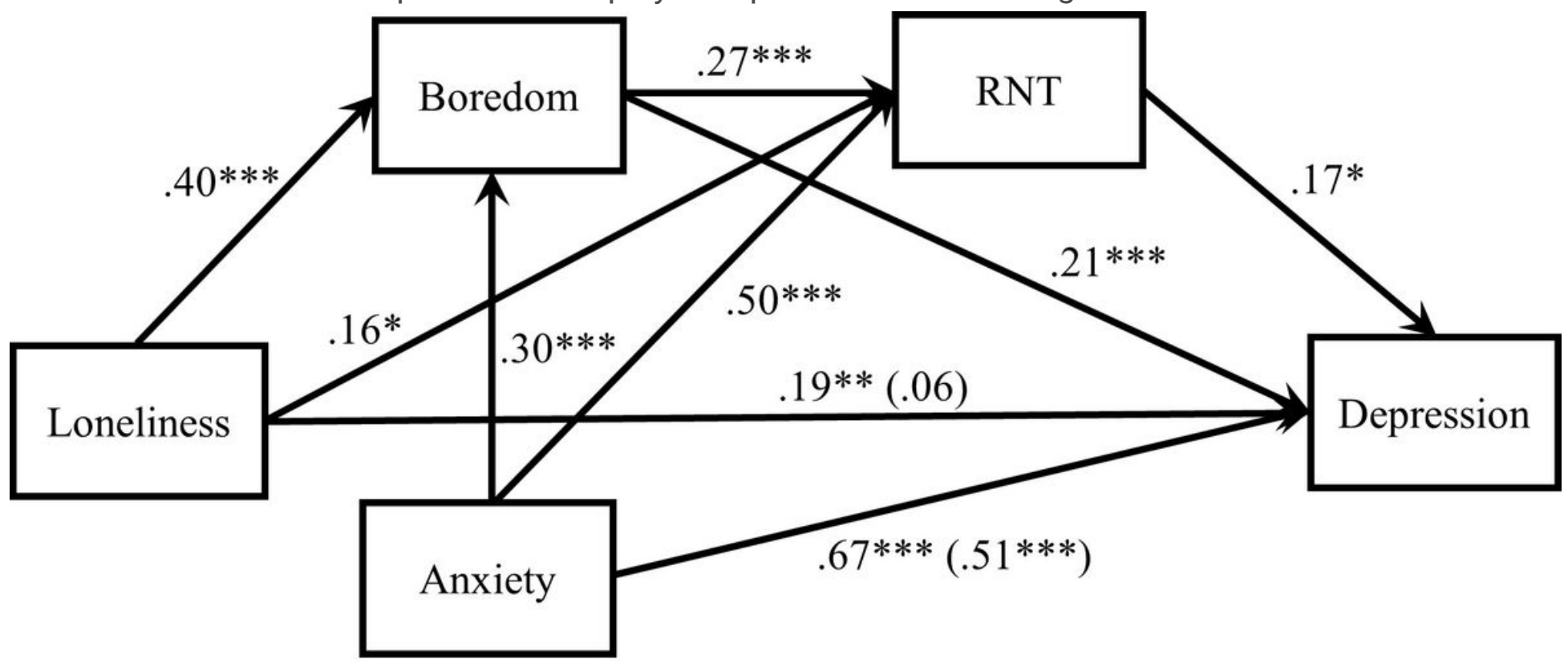

Figure 2

Indirect effects of loneliness on depression with anxiety as a covariate. Note. Coefficients are standardized. ${ }^{* \star} \mathrm{p}<.001,{ }^{\star \star} \mathrm{p}<.01,{ }^{\star} \mathrm{p}<.05$. The direct effects of Loneliness and Anxiety on Depression are displayed in parentheses following the total effects 